\title{
Different Brain Mechanisms Mediate Sensitivity to Sensory Consonance and Harmonic Context: Evidence from Auditory Event-Related Brain Potentials
}

\author{
Pascaline Regnault ${ }^{1}$, Emmanuel Bigand ${ }^{2}$, and Mireille Besson ${ }^{1}$
}

\begin{abstract}
The goal of this study was to analyze the time-course of sensory (bottom-up) and cognitive (top-down) processes that govern musical harmonic expectancy. Eight-chord sequences were presented to 12 musicians and 12 nonmusicians. Expectations for the last chord were manipulated both at the sensory level (i.e., the last chord was sensory consonant or dissonant) and at the cognitive level (the harmonic function of the target was varied by manipulating the harmonic context built up by the first six chords of the sequence). Changes in the harmonic function of the target chord mainly modulate the amplitude of a positive compo-
\end{abstract}

\section{INTRODUCTION}

The main purpose of the present study is to investigate the neural correlates of the sensory and cognitive processes $^{1}$ that govern musical, and more specifically, harmonic expectancy. To this end, we recorded the changes in the brain electrical activity associated with the presentation of chord sequences. Before describing the design of the experiment and the method we used, the processes that govern harmonic expectancy are examined in some details.

Harmonic expectancy is generated both by bottomup and top-down processes. Bottom-up processes reflect the influence of general principles of perceptual organization, such as melodic interval size and melodic contour (Cuddy \& Lunney, 1995; Krumhansl, 1995; Schellenberg, 1995; Unyk \& Carlsen, 1987; Boltz \& Jones, 1986; Carlsen, 1981). Top-down processes, in contrast, reflect the importance of the listeners' knowledge of a given musical idiom, like tonal-harmonic hierarchy (Bigand \& Pineau, 1997; Schmuckler, 1989; Schmuckler \& Boltz, 1994; Bharucha \& Stoeckig, 1986, 1987). Thus, in the Western tonal system, a chord may be unexpected based on its acoustic

\footnotetext{
${ }^{1}$ National Center for Scientific Research, Marseille, France,

${ }^{2}$ Université de Bourgogne, Dijon, France
}

nent peaking around $300 \mathrm{msec}$ (P3) after target onset, reflecting top-down influences on the perceptual stages of processing. In contrast, changes in the acoustic structure of the target chord (sensory consonance) mainly modulate the amplitude of a late positive component that develops between 300 and $800 \mathrm{msec}$ after target onset. Most importantly, the effects of sensory consonance and harmonic context on the event-related brain potentials associated with the target chords were found to be independent, thus suggesting that two separate processors contribute to the building up of musical expectancy.

features or on its harmonic function within the musical sequence.

The first most apparent factor governing harmonic expectancy is based on the acoustic features of chords: in Western music, a dissonant chord sounds as an unexpected event. When presented in isolation, the dissonance of a chord mainly depends on its perceived roughness (Helmholtz, 1877, chap. 10). Plomp and Levelt (1965) showed that the contribution to the roughness of a sound from a pair of pure-tone components is greatest when the distance between the components corresponds approximately to onequarter of a critical band (Moore \& Glasberg, 1983; Zwicker \& Terhardt, 1980; Plomp \& Levelt, 1965). Hutchinson and Knopoff (1978) formalized the findings of Plomp and Levelt in such a way that they may be applied to musical chords: relevant for the present study is the fact that chords with augmented fifth (e.g., C-E-G\#) have systematically greater roughness than perfect major or minor chord (i.e., chord with a perfect fifth, $\mathrm{C}-\mathrm{E}-\mathrm{G}$, for example). When played in isolation, augmented fifth chords are easily perceived as more dissonant than perfect major chord (Bigand \& Pineau, 1997).

When presented in a musical context, the sensory dissonance of a chord also depends on the strength of the harmonic pitch relationships with the preceding chords. As quoted from Schmuckler (1989, p. 134), "a 
chord sharing component tones, or overtones, with a preceding chord will be more highly anticipated than a continuation containing no overlapping frequencies with its predecessor." In the sensory model of Parncutt (1989), the strength of harmonic pitch relationships between successive chords (i.e., the pitch commonality value) is defined by the degree to which the two chords have perceived pitches in common, taking into account the relative perceptual salience of each pair of pitches. For example, the pitch commonality value is higher for the chords $\mathrm{C}$ and $\mathrm{G}$ (i.e., $\mathrm{C}-\mathrm{E}-$ $\mathrm{G}$ and $\mathrm{G}-\mathrm{B}-\mathrm{D}$, component tones, respectively) than for the chords $\mathrm{C}$ and $\mathrm{F} \#$ (i.e., $\mathrm{C}-\mathrm{E}-\mathrm{G}$ and $\mathrm{F} \#-\mathrm{A} \#-\mathrm{C \#}$; see Bigand, Parncutt, \& Lerdahl, 1996). In other words, after a C-major chord, an F\# chord creates more sensory dissonance than a G-major chord. For this reason, the $\mathrm{F} \#$ chord will sound more surprising in this context than a G-major chord.

In Western music, the second main factor that governs harmonic expectancy is the syntactic-like function of the chord. The function of a chord in a given musical context depends upon its place in the harmonic hierarchy established by the key. Harmonic hierarchy refers to a set of constraints, specific to the Western musical system, that have been interiorized by the listeners through passive exposure to Western musical pieces ${ }^{2}$ (Tillmann, Bharucha, \& Bigand, 2000; Krumhansl, 1990; Bharucha, 1987). A previous musical context activates listeners' knowledge of harmonic hierarchy, so that the most expected chords are the most related ones to the key context. Thus, harmonic expectancy mirrors harmonic hierarchy: The tonic chord of the underlying key context is more expected than all other chords. Chords that do not belong to the key context are the less expected ones (Schmuckler \& Boltz, 1994; Bharucha, 1987).

Although the sensory dissonance and the harmonic function of the chord apparently refer to clearly distinct processes, disentangling the respective influence of these processes remains difficult. Indeed, the theoretical accounts of harmonic hierarchy and psychoacoustical accounts of chordal dissonance are so intrinsically related (Krumhansl, 1990; Parncutt, 1989) that changes in the harmonic function of a target chord are most of the time confounded with changes in its acoustical features (see Bigand et al., 1996, for an attempt to disentangle the two factors). For example, after a C-major chord, a G-major chord will be more expected than a F\#-major chord for two confounded reasons: First, the $G$ chord fits better than the $\mathrm{F} \#$ chord in the harmonic hierarchy established by the $\mathrm{C}$-major chord ( $\mathrm{C}$ and $\mathrm{G}$ belong to the same key, but not $\mathrm{C}$ and $\mathrm{F} \#$ ). Second, the pitch commonality value for $C$ and $G$ chords is higher than for $C$ and F\# chords. Consequently, as long as different harmonic relations between the prime and the targets are instantiated via different target chords, the effects of sensory and cognitive processes on harmonic expectancy are necessarily confounded (see Bharucha \& Stoeckig, 1986).

In order to avoid this confound, it is possible to reduce the acoustic complexity of the musical sound so that the prime and the target chords do not share any common frequency (see Bharucha \& Stoeckig, 1987). The presence of harmonic priming in the absence of spectral overlap between the two chords demonstrates that harmonic expectancy occurs at a cognitive level of representation. An alternative possibility is to manipulate the harmonic function of the target chord, while keeping the target and its psychoacoustical characteristics constant (Bigand \& Pineau, 1997). In Bigand and Pineau (1997), eight chord sequences were presented to participants who were asked to decide whether the last chord (the target) was consonant or dissonant. Expectations for the last chord were varied by changing the harmonic context created by the first six chords. In one context, the last chord was part of an authentic cadence (i.e., a dominant chord followed by a tonic chord, V-I, see Rosner \& Narmour, 1992), while in the other context, the last chord took the form of a fourth harmonic degree following an authentic cadence (I-IV, see Figure 1a). The penultimate chord and the target chord were identical in both contexts. Although the change in the harmonic function achieved is subtle (tonic vs. subdominant harmonic function), it was hypothesized that participants' expectation would be stronger for the tonic than for the subdominant target chords. Results confirmed this prediction: Participants were faster and more accurate in deciding that the last chord was consonant or dissonant when it was strongly expected (the tonic) than when it was less expected (the subdominant). Pineau and Bigand (1997) replicated these findings with a larger set of chord sequences, and Bigand, Madurell, Tillmann, and Pineau (1999) extended them to longer chord sequences. In all experiments, effects of the harmonic function were found both for musically expert and naive participants. However, musicians were faster and more sensitive to sensory dissonance than nonmusicians. Sensory consonance (consonant vs. dissonant) and harmonic function of the target chord (tonic vs. subdominant) were also found to interact in both groups: The effect of harmonic function was stronger for the consonant targets.

To summarize, previous harmonic priming experiments (Bigand \& Pineau, 1997; Bigand et al., 1999; Bharucha \& Stoeckig, 1986) suggest that harmonic expectancy is influenced both by the acoustic features of a chord and by its harmonic function within the sequence. Moreover, previous results have revealed significant interactions between target type (consonant vs. dissonant) and changes in the harmonic function of the target (strongly vs. weakly expected). Therefore, these two factors may influence some common pro- 
Figure 1. (a) Example of musical sequences when the last chord is strongly (left) and weakly (right) expected. (b) Time-course within a trial. $\mathrm{C} 1$ to $\mathrm{C} 8=$ chords. $\mathrm{BL}=$ baseline. a.

TARGET CHORD STRONGLY EXPECTED TARGET CHORD WEAKLY EXPECTED

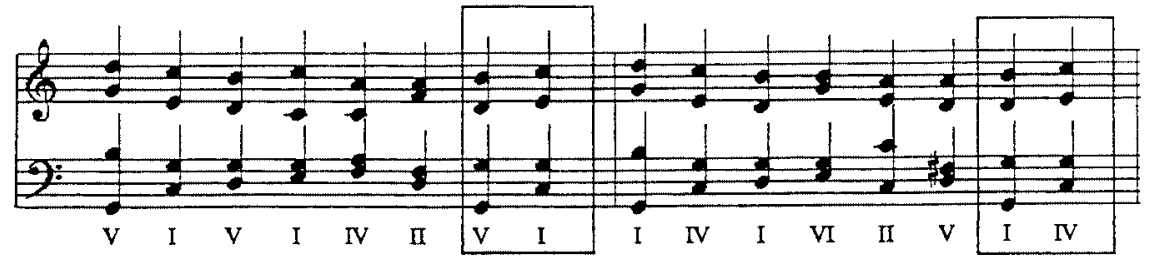

b.

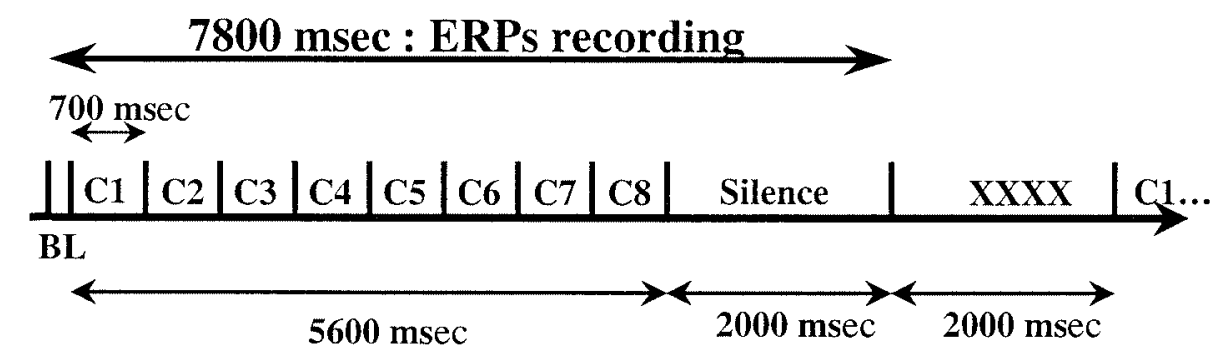

cessing stages. However, as both reaction times (RT) and percentage of correct responses only provide a measure of the end-up product of the processes involved, other methods are needed to further test this hypothesis.

The aim of the present experiment was to test this hypothesis using the event-related brain potential (ERP) method. Recording the changes in brain electrical activity that are time-locked to the presentation of a specific event (ERPs) allows one to follow the time-course of the different processes involved in musical expectancy. The ERP method presents the advantages of providing a continuous measure of the changes in brain electrical activity associated with the processing of a specific event. Moreover, it offers an excellent temporal resolution, of the order of the millisecond, and allows one to determine whether similar or different processes are engaged within a specific task, or are activated by a specific stimulus. Indeed, qualitatively different processes are reflected by qualitatively different ERP waveforms.

Previous experiments using ERPs to study music processing have shown that incongruous or "wrong" notes at the end of a melody elicit a late positive component (LPC), peaking between 500 and $600 \mathrm{msec}$ (Besson \& Macar, 1987; Besson, Fäita, \& Requin, 1994; Besson \& Faita, 1995). In the Besson and Faita (1995) experiment, the incongruity was either a nondiatonic note, out of the key, or a diatonic note out of the melodic line. The amplitude of the LPC was larger for nondiatonic than diatonic incongruities, that is, for the most unexpected notes. Thus, the LPC seems to be a good electrophysiological marker of musical expec- tancy. A similar conclusion was reached by Patel, Gibson, Ratner, Besson, and Holcomb (1998), Janata (1995), and Levett and Martin (1992) using harmonic sequences of chords. The finding that unexpected melodic or harmonic musical events elicit similar LPCs that develop between 300 and $800 \mathrm{msec}$ and peak around $600 \mathrm{msec}$ may suggest that a single general processor is involved in the detection of different musical expectancy violations. However, this interpretation should be considered with caution as sensory consonance and harmonic function were partly confounded in these previous experiments. To avoid such confound, it is necessary to manipulate these two different types of musical violations independently, and to determine whether or not they elicit similar ERP components.

To assess whether dissonance and violations of harmonic function are associated with similar or different ERPs effects, the chord sequences previously used by Bigand and Pineau (1997) and Pineau and Bigand (1997) were presented to the participants. The acoustic features and harmonic function of the target chords were factorially manipulated. In order to manipulate the acoustic features, half of the target chords were rendered acoustically dissonant by increasing the pitch of the fifth by a semitone (C-E-G\#, instead of $\mathrm{C}-\mathrm{E}-\mathrm{G})$. According to Hutchinson and Knopoff (1978), dissonant target chords have systematically greater roughness than consonant ones. In order to manipulate the harmonic function of the target chords, the final chord of the sequence either acted as a tonic chord (strongly expected) or as a subdominant chord (less expected). Based on the results of the ERP experiments described 
above, musical violations were expected to elicit a LPC. Of main interest was to determine whether the LPC would mainly reflect violations of the acoustic features of the chord, of its harmonic function, or of both. If the LPC is sensitive to both types of violations, it would then be important to determine whether the effects of sensory consonance and harmonic function are additive or interactive. Note, however, that changes in the acoustic features and in the harmonic function of the target chords may also modulate the amplitude of other ERP components than the LPC. If these ERP effects (whether on the LPC or on other ERP components) are additive, this would argue in favor of distinct processors for the different harmonic violations. In contrast, if the effects are not additive, i.e., they interact with each other, this would argue in favor of common processors.

In order to assess the effect of musical expertise on musical expectancy, and more specifically on the processing of sensory consonance and harmonic function, both musicians and nonmusicians participated in the experiment. Comparing results between these two groups enable us to highlight which aspects of music perception are immediately available to the listener and which aspects require formal training.

\section{RESULTS}

\section{Behavioral Data}

Musicians classified consonant and dissonant chords with an overall accuracy of 97\% (97.1\% of correct responses to consonant chords, $97.7 \%$ to dissonant chords). Nonmusicians also performed the task very well, with an overall accuracy of $81 \%$ (77.7\% of correct responses to consonant chords, $84.2 \%$ to dissonant chords).

\section{Event-Related Brain Potentials}

Grand average ERPs spanning the length of the entire recording period (7800 $\mathrm{msec}$ ) are shown in Figure 2 for three recording sites. A large N1/P2 complex followed by a large negativity is associated with each chord of the sequence. The N1/P2 component is larger for the first chord of the sequence and, due to the sensory refractory $^{3}$ period (see Näätänen \& Picton, 1987), decreases for the following chords. Interestingly, these ERPs are highly similar to those elicited by each word in a sentence context (see King \& Kutas, 1995). Note that clear-cut differences are found for both musicians and nonmusicians, between the final consonant and dissonant target chords (see Figure 2).

In order to examine these effects in more details, analyses were conducted on the mean amplitude of the ERPs waveforms time-locked to the onset of the final target chord, in the successive latency ranges described

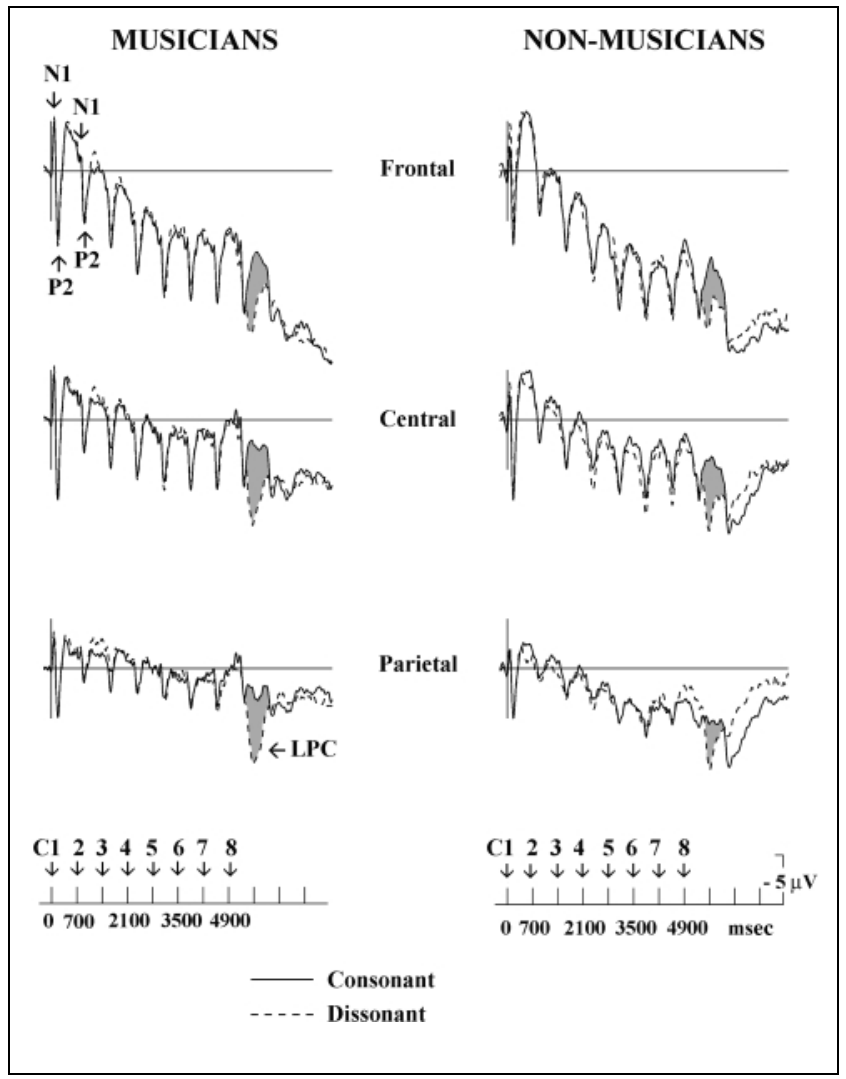

Figure 2. Grand average ERPs from the midline electrodes recorded across the sequences of eight chords (C1 to C8), when the last chord is consonant or dissonant (gray areas illustrate the ERP differences between the two conditions). In this figure as in the following ones, negativity is up.

below. Results regarding the effects of interest (i.e., main effects of expertise, consonance and context, and consonance by context interaction) are always reported. The other effects, specifically the interactions between factors, and the results of separate analyses for musicians and nonmusicians are only reported when they are significant. Table 1 summarizes the results of the analyses. Note that we use chronological order to describe the ERP components that are identifiable from the traces (i.e., P3 is the third component). Top of Figures 3 and 4 shows the effect of sensory consonance in musicians and nonmusicians, respectively, whereas the bottom of these figures shows the effect of harmonic context.

In the 0-100-msec range, a negative peak, N1, is found for musicians whereas a positive shift is found for nonmusicians. Results of analysis of variances (ANOVAs) showed that the main effect of expertise was significant $[F(1,22)=5.79, p<.02]$ : The ERPs were overall negative for musicians $(-0.28 \mu \mathrm{V})$, whereas they were overall positive for nonmusicians $(0.58 \mu \mathrm{V})$. Furthermore, the effect of consonance interacted with the effect of expertise $[F(1,22)=5.74, p<.02]$. Separate analyses for musicians and nonmusicians showed that such early effect of consonance was significant only for musicians, 
Table 1. Results of the Statistical Analyses in the Different Latency Ranges as a Function of the Different Factors

\begin{tabular}{lccccccccccccccc}
\hline & $A$ & $B$ & $A B$ & $C$ & $A C$ & $B C$ & $A B C$ & $D$ & $A D$ & $B D$ & $A B D$ & $C D$ & $A C D$ & $B C D$ & $A B C D$ \\
\hline $0-100 \mathrm{msec}$ & + & - & - & $\mathrm{M}$ & + & - & - & $+/ \mathrm{M} / \mathrm{NM}$ & - & - & - & - & - & - & - \\
$100-200 \mathrm{msec}$ & + & - & - & - & + & - & - & $+/ \mathrm{M} / \mathrm{NM}$ & - & - & - & - & - & - & - \\
$200-300 \mathrm{msec}$ & - & + & - & - & - & - & - & + & - & - & - & - & - & - & - \\
$300-800 \mathrm{msec}$ & - & - & - & + & - & - & - & + & - & + & - & + & - & - & - \\
$1000-1500 \mathrm{msec}$ & - & + & - & + & - & - & - & + & - & - & - & + & - & - \\
$1600-2600 \mathrm{msec}$ & + & - & - & - & - & - & - & $+/ \mathrm{M}$ & - & $\mathrm{NM}$ & + & - & - & - & - \\
\hline
\end{tabular}

$+=$ significant effects $(p<.05)$ when all subjects are combined; $\mathrm{M}=$ significant effects for musicians only; NM $=$ significant effects for nonmusicians only.

$\mathrm{A}=$ expertise $; \mathrm{B}=$ context $\mathrm{C}=$ consonance; $\mathrm{D}=$ electrodes.

with larger $\mathrm{N} 1$ components to consonant $(-0.61 \mu \mathrm{V})$ than to dissonant $(0.05 \mu \mathrm{V})$ target chords (main effect of consonance: for musicians, $F(1,11)=5.51, p<.03$; for nonmusicians, $F(1,11)=1.05, p>.30)$. N1 amplitude was not modulated by the harmonic function of the target chord (main effect of context: $F(1,22)=1.75 ; p=$ .20). The sensory Consonance $\times$ Context interaction was not significant $(F<1)$.

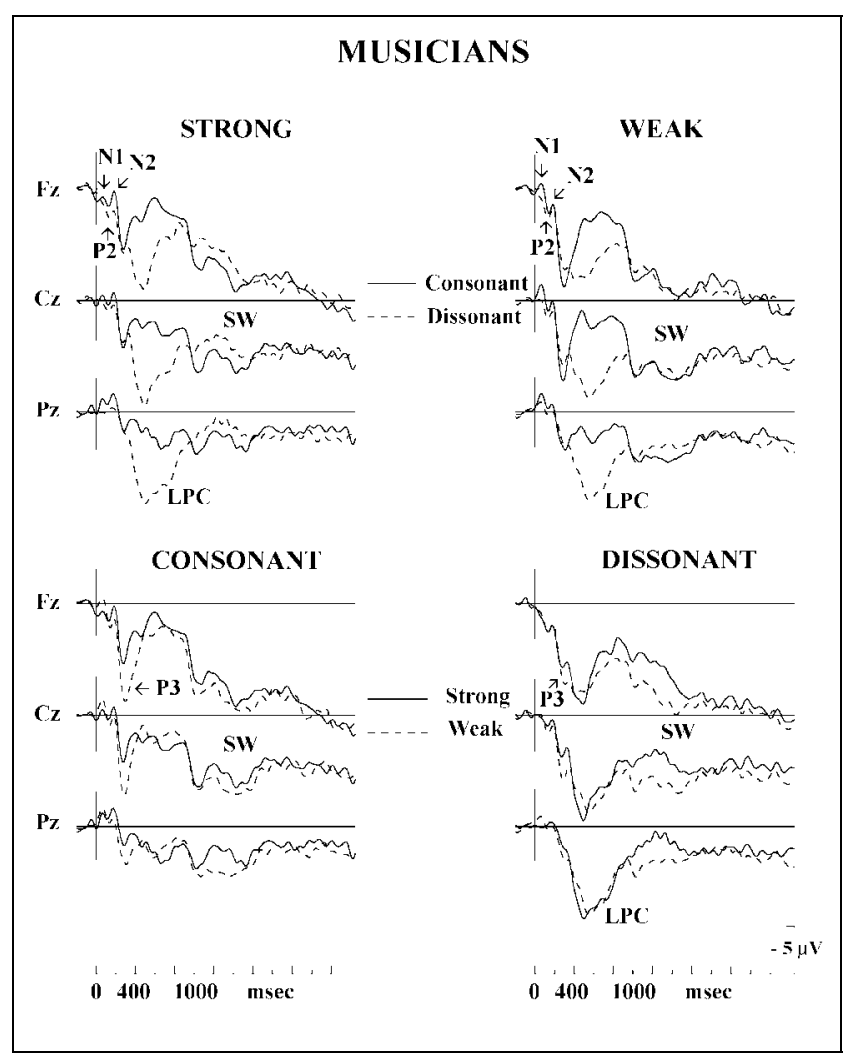

Figure 3. Grand average ERPs recorded from 12 musicians, at the midline electrodes, and time-locked to the onset of the target chord. Top: Comparison between consonant and dissonant chords when they are strongly (left) and weakly (right) expected. Bottom: Comparison between strongly and weakly expected chords when they are consonant (left) and dissonant (right).
In the 100-200-msec range, a P2/N2 complex is found for musicians whereas a positive shift can be seen for nonmusicians. Results of ANOVAs showed that the main effect of expertise was significant $[F(1,22)=15.22$, $p<$ $.001]$ : The ERPs were overall less positive for musicians $(0.14 \mu \mathrm{V})$ than for nonmusicians $(1.85 \mu \mathrm{V})$. Furthermore, the effect of sensory consonance interacted with the effect of expertise $[F(1,22)=6.14, p<.02]$ : while

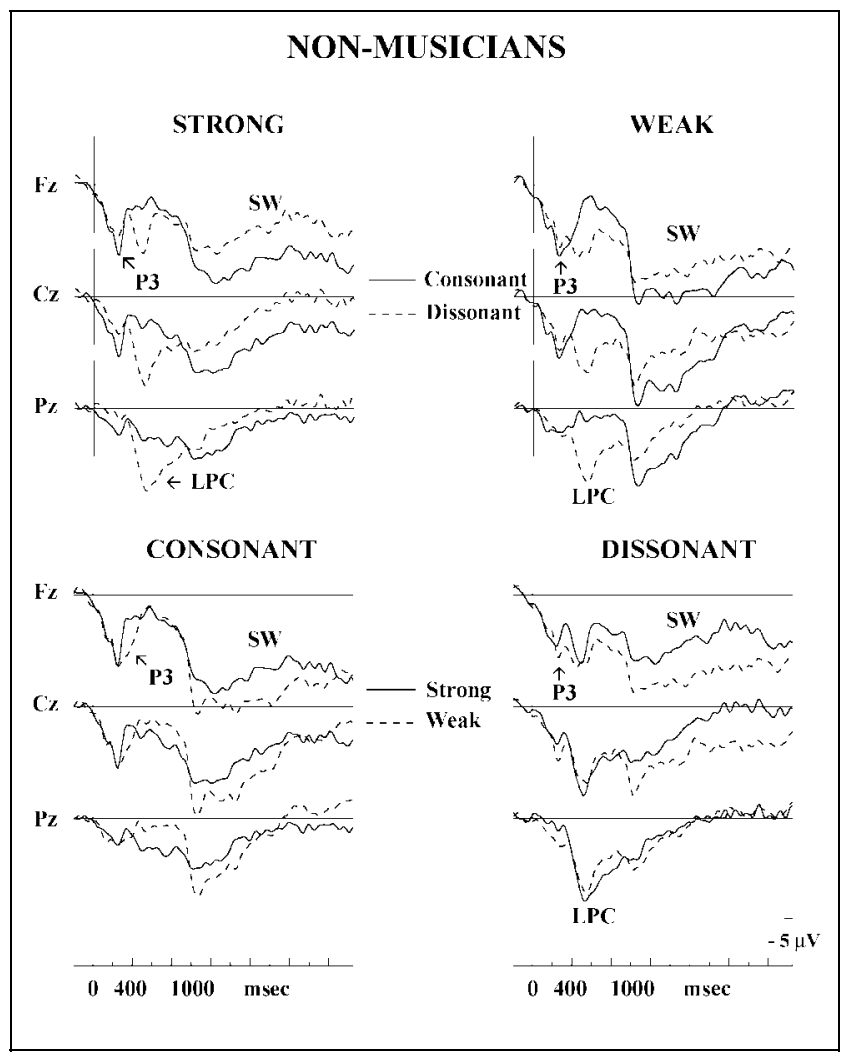

Figure 4. Grand average ERPs recorded from 12 nonmusicians, at the midline electrodes, time-locked to the onset of the target chord. Top: Comparison between consonant and dissonant chords when they are strongly (left) and weakly (right) expected. Bottom: Comparison between strongly and weakly expected chords when they are consonant (left) and dissonant (right). 


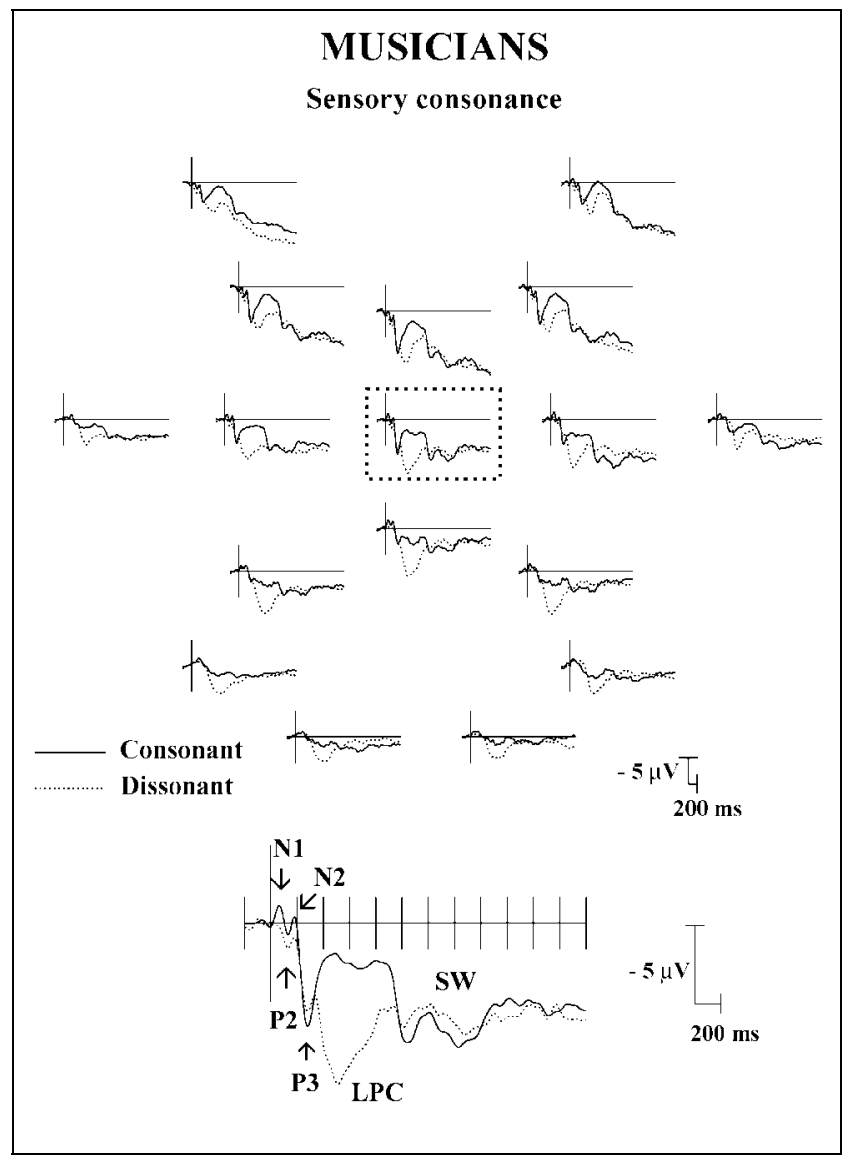

Figure 5. Grand average ERPs recorded from 12 musicians and from 17 electrodes (top) when the target chord is consonant or dissonant. ERPs recorded in the strongly and weakly expected conditions are collapsed in these averages.

for musicians dissonant targets $(0.51 \mu \mathrm{V})$ elicited larger P2 components than consonant targets $(-0.21 \mu \mathrm{V})$, the reverse was found for nonmusicians $(1.56 \mu \mathrm{V}$ for dissonant, $2.14 \mu \mathrm{V}$ for consonant chords). The main effect of context was not significant $[F(1,22)=1.18 ; p>.30]$. The sensory Consonance $\times$ Context interaction was not significant $(F<1)$.

In the 200-300-msec range, large $\mathrm{P} 3$ components are elicited in both groups. Results of ANOVAs showed that the main effect of expertise was not significant $(F<1)$. Nor was the main effect of sensory consonance $[F(1$, $22)=2.44 ; p>.10]$. In contrast, the main effect of context was significant $[F(1,22)=4.46, p<.04]$ : across groups, larger P3s were elicited by weakly $(2.73 \mu \mathrm{V})$ than by strongly $(2.00 \mu \mathrm{V})$ expected chords. This effect lasted until $400 \mathrm{msec}$ for nonmusicians [main effect of context: $F(1,11)=6.38, p<.02$ ]. The sensory Consonance $\times$ Context interaction was not significant $(F<1)$.

In the 300-800-msec range, a large LPC is associated with dissonant chords. Results of ANOVAs showed that the main effect of expertise was not significant $(F<1)$ so that this large effect of sensory consonance was found for both musicians and nonmusicians $[F(1,22)=53.07$, $p<.0001]$ : LPCs were larger when the target chord was dissonant $(4.56 \mu \mathrm{V})$ than when it was consonant $(1.88$ $\mu \mathrm{V})$. Furthermore, while the main effect of context was not significant $(F<1)$, the Context $\times$ Electrodes interaction was significant $[F(16,352)=5.80, p<.0001]$ : At the frontal site $(\mathrm{Fz})$, larger positivity was associated with weakly $(5.39 \mu \mathrm{V})$ than strongly $(4.17 \mu \mathrm{V})$ expected chords. Finally, the sensory Consonance $\times$ Context interaction was again not significant $(F<1)$.

In the 1000-1500-msec range, a positive shift is elicited by the target chords in all conditions for both musicians and nonmusicians. Results of ANOVAs showed that the main effect of expertise was not significant $(F<1)$. In contrast, the main effect of sensory consonance was significant $[F(1,22)=4.49$, $p<.04]$, but reverse to the effect found in the 300800-msec range: Consonant chords elicited more positivity $(5.61 \mu \mathrm{V})$ than dissonant chords $(4.55 \mu \mathrm{V})$. The main effect of context was also significant $[F(1,22)=$ $7.07, p<.01]$ : Weakly expected chords elicited a larger positivity $(5.69 \mu \mathrm{V})$ than strongly expected chords

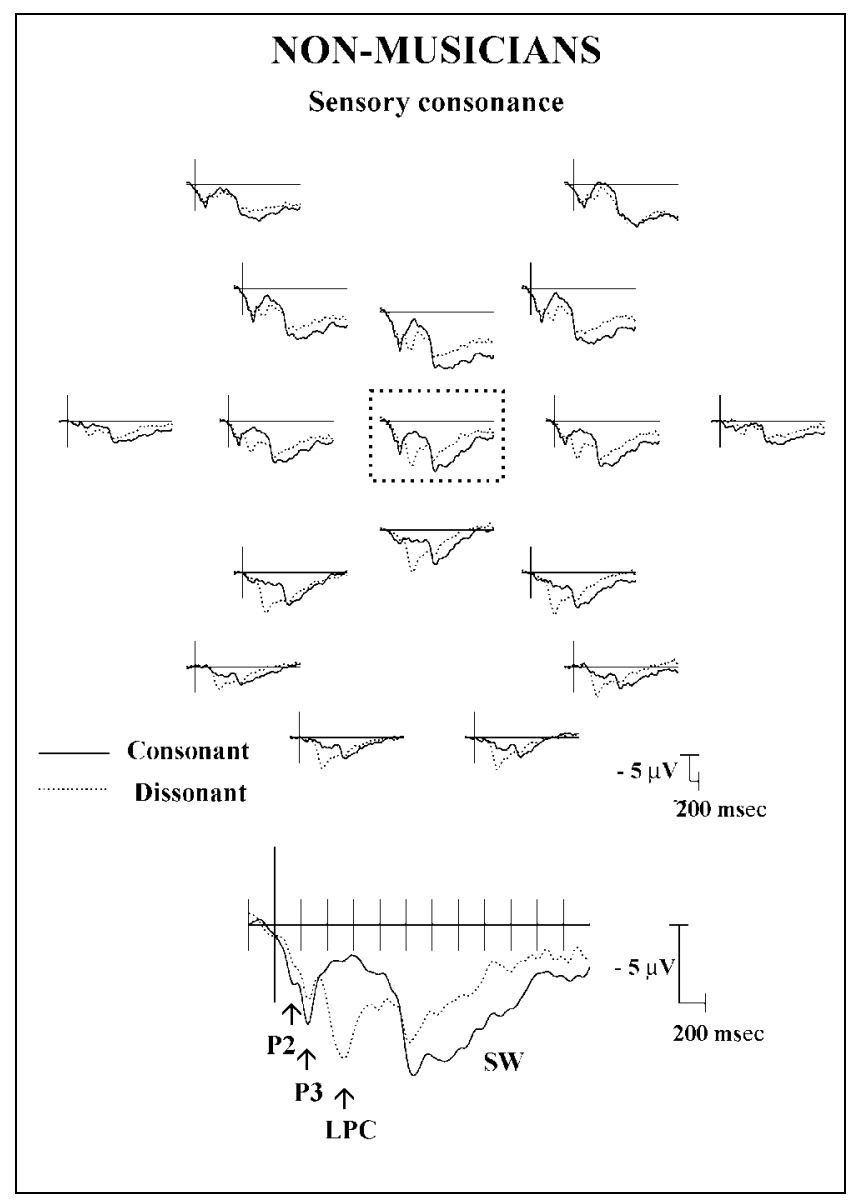

Figure 6. Grand average ERPs recorded from 12 nonmusicians and from 17 electrodes (top) when the target chord is consonant or dissonant. ERPs recorded in the strongly and weakly expected conditions are collapsed in these averages. 


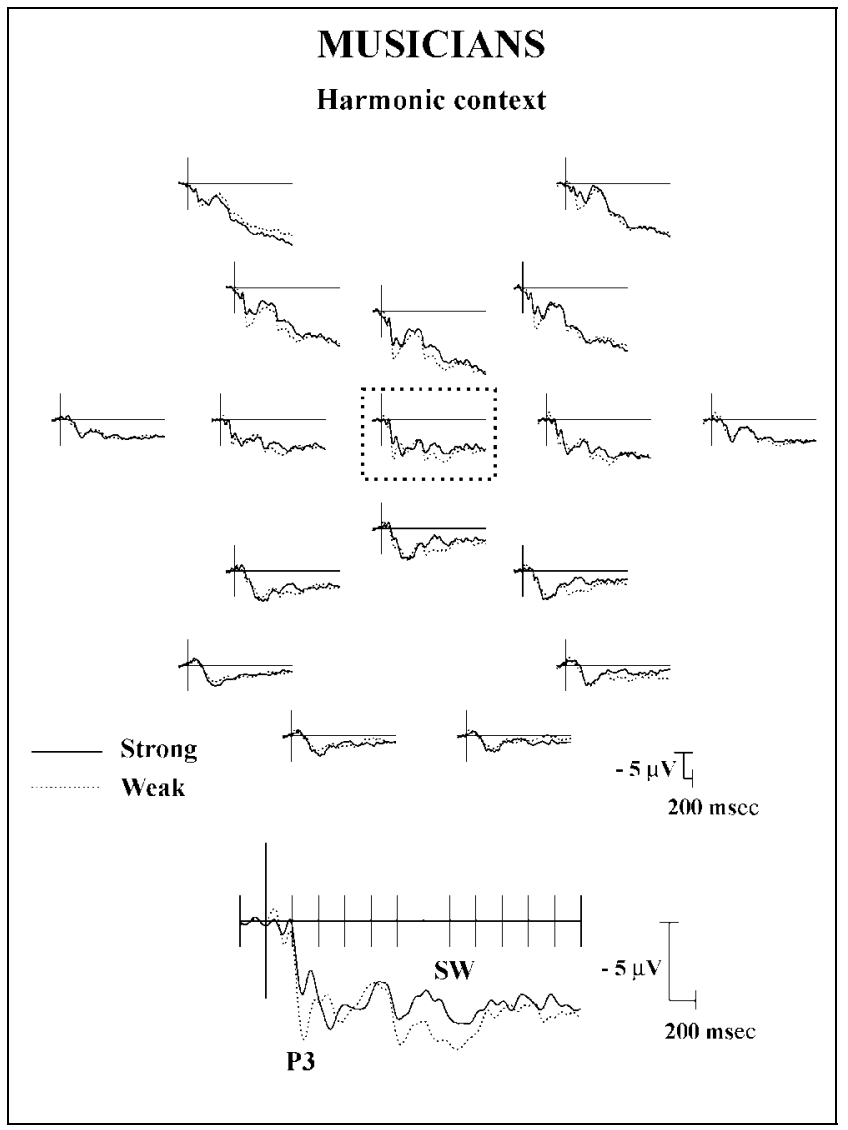

Figure 7. Grand average ERPs recorded from 12 musicians and from 17 electrodes (top) when the target chord is strongly or weakly expected. ERPs recorded in the consonant and dissonant conditions are collapsed in these averages.

$(4.47 \mu \mathrm{V})$. Finally, the sensory Consonance $\times$ Context interaction was not significant $(F<1)$.

In the 1600-2600-msec range, there was no difference between conditions for musicians: The ERP traces in all four conditions nicely came back together. In contrast, for nonmusicians, effects similar to those described in the 1000-1500-msec range were also apparent in this latency range. Results of ANOVAs showed that the main effect of expertise was significant $[F(1,22)=5.88 ; p<.02]$ : ERPs were more positive for musicians $(5.30 \mu \mathrm{V})$ than for nonmusicians $(2.77 \mu \mathrm{V})$. The effect of sensory consonance was not significant $(F<1)$. In contrast, the effect of context was significant for nonmusicians only, with a frontal maximum [Context $\times$ Electrodes interaction: $F(16,176)=3.74$, $p<.005$ ]: weakly expected targets elicited a larger positivity $(8.64 \mu \mathrm{V})$ than strongly expected targets $(5.95$ $\mu \mathrm{V})$. Finally, the sensory Consonance $\times$ Context interaction was not significant $(F<1)$.

In order to illustrate the effects of sensory consonance independently of context, ERPs to consonant chords weakly expected were averaged together with the ERPs to consonant chords strongly expected, and ERPs to dissonant chords weakly expected were averaged together with the ERPs to dissonant chords strongly expected (see Figures 5 and 6). Similarly, to illustrate the effects of harmonic context independently of consonance, ERPs to weakly expected chords were collapsed across consonant and dissonant chords, and ERPs to strongly expected chords were collapsed across consonant and dissonant chords (see Figures 7 and 8).

To summarize, the main results show an early effect of consonance in the 0-100-msec range for musicians only: N1s were larger to consonant than dissonant chords (see Figure 5). In the 100-200-msec range, consonance interacted with expertise: While musicians showed larger P2s to dissonant than consonant chords, nonmusicians showed larger P2s to consonant than dissonant chords (see Figures 5 and 6). In the 200-300-msec range, the effect of harmonic context was significant for both musicians and nonmusicians: P3s were larger for weakly than strongly expected chords (see Figures 7 and 8 ). In the 300-800-msec range, the effect of consonance was also significant for both musicians and nonmusicians: LPCs were larger to dissonant than consonant chords (see Figures 5 and 6). In the 1000-1500msec range, the effects of consonance and context were significant for both nonmusicians and musicians: The

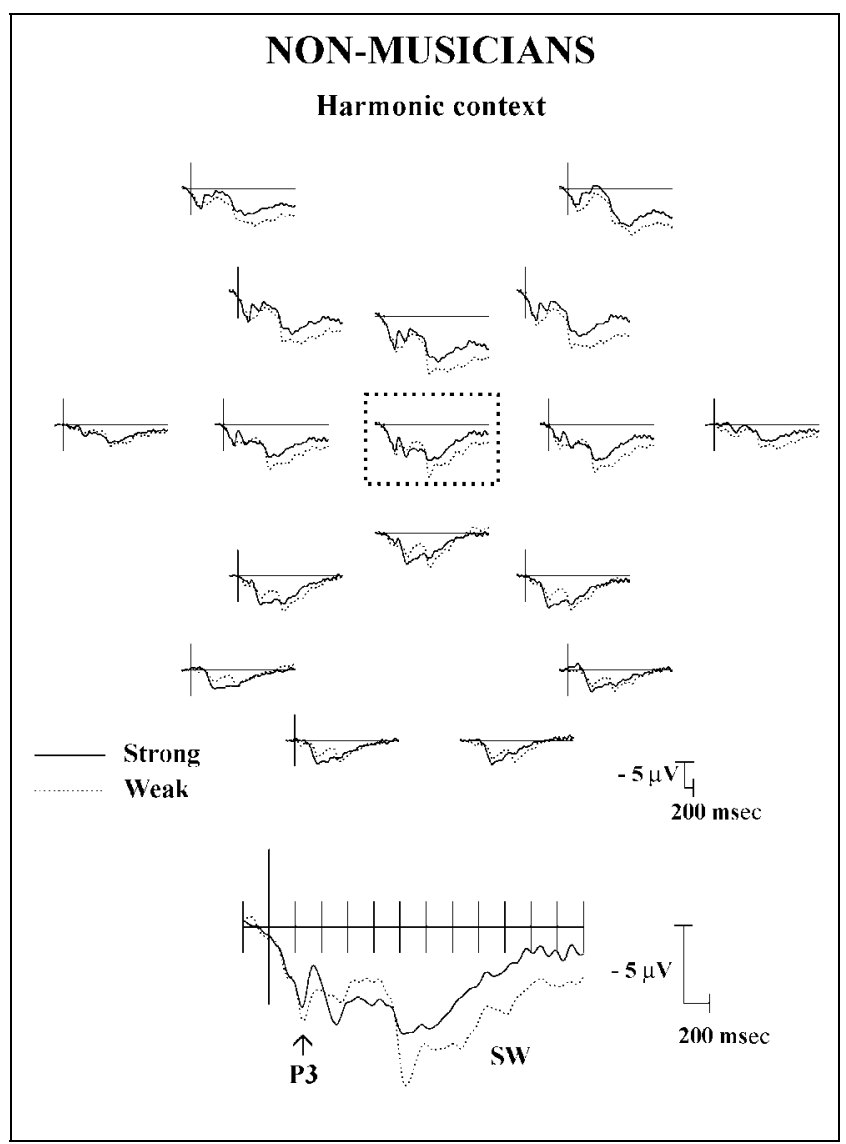

Figure 8. Grand average ERPs recorded from 12 nonmusicians and from 17 electrodes (top) when the target chord is strongly or weakly expected. ERPs recorded in the consonant and dissonant conditions are collapsed in these averages. 
positive shift was larger to consonant than dissonant chords (see Figures 5 and 6), and to weakly than strongly expected chords (see Figures 7 and 8). In the 1600-2600-msec range, there was an interaction between context and electrodes for nonmusicians only: The positive shift was larger to weakly than strongly expected chords at frontal sites (see Figure 8). For none of the identified components was the interaction between the effects of consonance and harmonic context significant.

\section{DISCUSSION}

The aim of the present experiment was to disentangle the effects of consonance and harmonic context on the formation of harmonic expectancy. Chord sequences were constructed so that the final two chords were identical across conditions, but the harmonic context before the final chords varied among conditions. Therefore, and this is the most important point, the harmonic function of the final target chord varied, while its psychoacoustical characteristics remained constant. Four experimental conditions were used: The final target chord was either consonant ( $\mathrm{C}-\mathrm{E}-\mathrm{G}$ for example) or dissonant ( $\mathrm{C}-\mathrm{E}-\mathrm{G} \#)$ and was either the expected tonic chord or a weakly expected subdominant chord. ERPs were used in order to analyze the time-course of the processes involved when we listen to chord sequences. In previous ERP studies, harmonically unexpected events have been shown to elicit LPCs, peaking around 600 msec (Patel et al., 1998; Besson \& Macar, 1987; Besson et al., 1994; Besson \& Faïta, 1995; Janata, 1995; Levett \& Martin, 1992).

The present findings are in line with these results. As predicted, dissonant chords elicited large LPCs, between 300 and $800 \mathrm{msec}$, for both musicians and nonmusicians. This result replicates previous findings with out-of-key notes at the end of melodies (Besson \& Macar, 1987; Besson \& Faïta, 1995; Paller, McCarthy, \& Wood, 1992; Verleger, 1990), and with either dissonant chords (Levett \& Martin, 1992) or harmonically unrelated chords (Patel et al., 1998; Janata, 1995). Levett and Martin (1992) used eight chord sequences, that, in one condition, ended with a harmonic error creating a dissonance (i.e., a semitone pitch alteration). Errors were associated with a positive component peaking at 650 msec. Janata (1995) presented three chord sequences, followed by the best expected (tonic), a harmonically plausible (the relative minor), or a harmonically implausible (unrelated) chord (the tonic of a distant tonality). The amplitude of the positive component (called P3b) was largest to unrelated chords, then to minor chords, and smallest to tonic chords. However, these amplitude differences between resolutions were small. Finally, Patel et al. (1998) presented musical phrases in which the target chord was the most expected one (e.g., a C-major chord for C-major key musical phrase), a chord of a nearby key (e.g., an Ebmajor chord for a C-major key musical phrase), or a chord of a distant key (e.g., a C\# major chord for a $\mathrm{C}$ major key musical phrase). The largest positivity was generated in the $500-800-\mathrm{msec}$ range by distant-key chords, then by nearby-key chords, and the smallest by in-key targets. Thus, in all of these studies using chord sequences, harmonically incongruous chords elicited large LPCs, like in our experiment.

However, the effects of consonance and harmonic context may have been partly confounded in these experiments. For examples, the out-of-key notes at the end of melodies used by Besson and Faita (1995), and the unrelated chords used by Janata (1995), were both harmonically implausible and dissonant because of their weak pitch commonality values with the preceding ones. In a related vein, the chords from the distant key, used by Patel et al. (1998), had lower pitch commonality values with the chords of the previous context than those of nearby-key and same-keys. As a consequence, chords in the distant-key condition were less expected both at the sensory and cognitive level. The main interest of the present results is that they succeed in disentangling the effects of sensory consonance and harmonic function at a neurophysiological level. Clearly, the main effect of consonance was found on the LPC amplitude, which was larger to dissonant than consonant chords in the 300-800-msec latency range. This effect was found both for musicians and nonmusicians, but was larger for musicians.

The main effect of harmonic context was significant earlier, in the 200-300-msec latency range, and was similar for musicians and nonmusicians. The amplitude of the P3 component was larger to the less expected subdominant chords than to the most expected tonic chords. Thus, both musicians and nonmusicians were sensitive to changes in the harmonic function of the target chord. They were able to differentiate between chords that were strongly expected and chords that were less expected as a function of the harmonic context, even when the task was not to pay attention to the harmonic context. This result is interesting for several reasons. First, it shows an effect of harmonic context even when the weakly expected chord still belongs to the tonality of the sequence, so that the difference between weakly and strongly expected chords is subtle. Second, this result reveals that nonmusicians, who never had any explicit learning of musical theory, clearly have an implicit knowledge of Western tonal harmony since they generate effects similar to those found for musicians (see Tillmann et al., 2000). Third, it demonstrates that harmonic expectancies do not only occur sequentially from chord to chord, since the last two chords were the same for strong and weak harmonic contexts, but also depend upon the harmonic function of the chord in the extended temporal context (Bigand \& Pineau 1997; 
Bigand et al., 1999; Tillmann, Bigand, \& Pineau, 1998). Finally, it shows that a cognitive effect preceded a sensory effect. This interesting and important finding deserves some further comments.

Two alternative interpretations can account for the findings that the cognitive effect of harmonic context (200-300 msec) occurs earlier than the sensory effect of consonance (300-800 msec). First, it may be that the sensory processing of musical stimuli requires complex auditory processing and is therefore a rather late process, reflected in the LPC (300-800 msec). Evidence for this interpretation comes from behavioral studies showing long RTs (1000 msec or above) to decide whether a chord is consonant or not (e.g., Bigand \& Pineau, 1997) and from ERP studies showing, for instance, that the LPC elicited by a word sung out of key (400-1000 msec) has a longer latency than the N400 elicited by semantically incongruous words (50-600 msec; Besson et al., 1998). Thus, if sensory processing is slow, the effect of harmonic context reflected in P3 (200-300 msec), that built up over the presentation of the different chords of the sequence and is therefore an anticipatory process, may indeed occurs before the sensory processing of the chords is completed. Second, one may argue that the long latency of the LPC (300-800 msec) makes it unlikely that the LPC is directly related to sensory processing. Rather, the LPC may reflect the outcome of such processes and the decision that the chord is dissonant. Partial evidence for this interpretation comes from results by Besson and Faita (1995) showing that the amplitude of the LPC is larger for musicians than nonmusicians when an explicit decision regarding the type of terminal note is required from the participants (a result also found with chords in the present study), but is not when they are passively listening to the melodies. Therefore, LPC amplitude is modulated by decisionrelated processes. It is, however, important to note that, in their experiment, the LPC to out-of-key notes was present independently of whether or not a decision was required. Consequently, the LPC does not only reflect such decision-related process but does also encompass the different aspects of sensory processing on which the decision is based. Clearly, more data are needed to disentangle these two interpretations.

Finally, recent results by Tekman and Bharucha (1998) are relevant to this issue. In order to track the time-course of sensory and cognitive priming, they presented two types of target: one was psychoacoustically similar to the prime (say C- and E-major chords), while the other was closely related on the basis of harmonic convention (say C- and D-major chords). A C-major prime shares a tone with an E-major target but does not share a tone with a D-major target; yet D-major is more closely related to the prime in conventional usage, since C- and D-major chords both belong to the G-major key. By contrast, C- and E-major chords do not share parent key. Priming results revealed facilitation for psy- choacoustically similar targets when they followed after a short (50 msec) stimulus onset asynchrony (SOA), and facilitation for harmonically related targets after a longer SOA (500 msec or longer). Thus, while both psychoacoustic similarity and harmonic relatedness seem to drive priming, the influence of the former seems shortlived. For longer SOAs, cognitive factors predominate over psychoacoustic ones, and lead to facilitate the processing of the sensory consonance of chords.

Regarding the aims of the present experiment, the critical aspect of our results is to demonstrate that the main effects of consonance and harmonic context were most often significant in different latency ranges, and consequently, mostly affected different ERPs components. Moreover, even when these two effects developed in the same latency range and affected the same ERP components, they were never found to interact with one another. Clearly, the differences in P3 amplitude associated with weakly and strongly expected target chords were not influenced by whether the final chord was consonant or dissonant. Similarly, the differences in LPC amplitude associated with dissonance were not affected by the characteristics of the harmonic context: Violations of consonance were processed similarly, irrespective of whether or not they were accompanied by harmonic context violations.

Taken together, these results strongly argue for an independent processing of sensory consonance and harmonic function of the target chords. They demonstrate that harmonic expectancy is not a unitary process, but rather encompasses sensory and cognitive aspects. From this point of view, the present study did not replicate the interactive effects of sensory consonance and harmonic function that has been reported in some behavioral studies. However, it should be noted that this two-way interaction is not consistently found in music perception research. In some cases, the two-way interaction between sensory consonance and harmonic function takes the form of a crossed interaction, with the processing of consonant target chords facilitated in the expected context, and inhibited in the weakly expected context (Tillmann et al., 1998; Tekman \& Bharucha, 1992; Bharucha \& Stoeckig, 1986, 1987). In other cases, this finding has not been replicated (see Bigand \& Pineau, 1997; Bigand et al., 1999; Tekman \& Bharucha, 1998). Usually, the effect of the harmonic function of the target chord simply tends to be stronger for consonant than for dissonant targets. Our finding of an independent processing of sensory consonance and harmonic function in chord sequences is in line with results from a case study of impaired auditory perception. Tramo, Bharucha, and Musieck (1990) examined a case of cortical hearing loss under experimental conditions designed to tap selectively into sensory, perceptual, and cognitive functions mediating tonal information processing. While the perception of the tonal spectra was severely impaired (with the apparent loss of tonal con- 
sonance perception), the cognitive representations of Western harmony was preserved as shown by significant harmonic priming effects. These findings suggest that sensory, perceptual, and cognitive processing of musical stimuli may be neurologically dissociable.

An interesting but difficult issue is to determine how the positivities reported in this experiment relate to those elicited by nonmusical stimuli. Positivities that belong to the P3 family or neighborhood (Donchin, 1999) are elicited by many different factors, such as novelty, subjective and objective probability, deviance, etc. The characteristics of these components in terms of latency, amplitude, and topographical distribution are sensitive to many factors, such as attention, memory, level of difficulty, and the tasks being performed. Therefore, determining whether the positivities elicited by different stimuli and tasks reflect similar or different processes requires to control these factors within a single experiment. A good example is the study by Patel et al. (1998) in which they directly compared the positivities elicited by syntactic violations in language (changes in word order) with those elicited by harmonic structure violations in music (changes in the harmonic function of the chords). Results revealed no significant difference in the positivities associated with linguistic and musical processing, which points to the similarity of the processes involved in both cases. Whether the LPC and $\mathrm{P} 3$ described in the present experiment reflect processes similar to those elicited by nonmusical stimuli remains an open issue. In any event, the important point is that even if the LPC and P3 are not specific to music, both components are sensitive to some aspects of musical expectancy and therefore provide useful tools to study music perception.

Aside from the main finding of an independent processing of sensory consonance and harmonic function of the target chords discussed above, the present results also revealed that these two factors had an influence on other ERP components. These results are discussed below.

An early effect of consonance was found for musicians, with consonant chords associated with significantly larger negative components, $\mathrm{N} 1,{ }^{4}$ than dissonant chords, in the 0-100-msec range. Thus, musicians differentiate consonant from dissonant chords at an early stage of processing. Note that N1 amplitude has also been shown to be modulated by attention: N1 is larger for attended than for unattended stimuli (Näätänen, Gaillard, \& Mantysalo, 1978; Näätänen, 1990; Hillyard, Hink, Schwent, \& Picton, 1973). However, an attention interpretation does not provide an explanation for the finding reported here, since participants had to pay equal attention to both consonant and dissonant chords in order to correctly perform the task. Furthermore, if it was attentional, such an effect should be found for nonmusicians as well. However, for nonmusicians, target chords, whether consonant or dissonant, did not elicit clear N1 components, and no difference was found as a function of consonance in this latency range. Thus, nonmusicians do not seem to differentiate consonant and dissonant chords as early as musicians. These findings are in line with those reported by Bigand et al. (1999) and Pineau and Bigand (1997) showing that musicians are usually faster and more sensitive to consonance than nonmusicians. Furthermore, while a clear succession of ERP components N1, P2, and N2, can be seen for musicians in the 0-200-msec range, no such components can be observed for nonmusicians. As these components are usually regarded as reflecting the processing of the physical attributes of a stimulus (Coles \& Rugg, 1995), these qualitative differences between musicians and nonmusicians may reflect the greater abilities of musicians to analyze the physical properties of sounds.

Such an interpretation is supported by the results of several experiments showing evidence for auditory cortical plasticity (see Rauschecker, 1999 for a review). Relevant for the present study is the finding by Pantev et al. (1998), using the magneto-encephalographic (MEG) method, that musicians have an increased auditory cortical representation of musical sounds compared to nonmusicians. Musicians and nonmusicians listened passively to unattended pure or piano tones while watching cartoon videos. Results showed enlarged dipole moments in the N1 latency range to piano tones only and for musicians only. Such increases in the strength of activation of the cortical sources event depends upon the age when musicians began to practice their instrument (the younger, the larger). Thus, musical expertise produces interesting functional reorganizations of the auditory cortices.

To summarize, our results clearly point to different ERP patterns for musicians and nonmusicians. Highly trained musicians showed changes in the N1, P3, and LPC according to sensory consonance and harmonic context, while nonmusicians showed modulations of the P3 and LPC. Such an early effect of consonance for musicians has not, to our knowledge, been described in previous ERP studies of consonance violations (Patel, 1998; Besson \& Macar, 1987; Besson \& Faïta, 1995; Janata, 1995; Paller et al., 1990; Verleger, 1990). In most of these experiments (Besson \& Macar, 1987; Besson \& Faïta, 1995; Paller et al., 1992; Verleger, 1990), consonance was examined within melodic contexts: Dissonances were produced by single tones out of the melodic key, or in key but not the most expected ones. Thus, they were dissonant only in reference to the previous context, not on the basis of their physical attributes. Chords, in contrast, can sound dissonant in isolation, depending on their perceived roughness (Helmholtz, 1877, chap. 10). In the experiments that used chord sequences as stimuli (Patel et al., 1998; Janata, 1995; Levett \& Martin, 1992), Levett and Martin (1992) were the only ones to use chords that sounded 
dissonant in isolation. However, the authors did not report any effect of consonance on the "early" components.

Late effects of both sensory consonance and harmonic context were also found between 1000 and $1500 \mathrm{msec}$, with larger positivities to consonant and weakly expected chords than to dissonant and strongly expected chords. Interestingly, for musicians, these effects clearly terminated by $1500 \mathrm{msec}$ post-target chord onset, so that the ERPs in the four experimental conditions were very similar from $1500 \mathrm{msec}$ until the end of the recording period. In contrast, the effect of context lasted longer for nonmusicians and was still significant between 1600 and $2600 \mathrm{msec}$. Such late effects (from $1500 \mathrm{msec}$ ) are reminiscent of the slow wave (SW) activity, described by MacCallum et al. (1989) as dependent upon the demands imposed on the processing resources. In our experiment, this SW activity seems to reflect the decision, based on the sensory analysis of the acoustic features of the target chord within its specific harmonic context, that the chord is consonant or dissonant. Its mean latency, around $1300 \mathrm{msec}$ post-target chord onset, is indeed compatible with the RTs obtained in previous experiments (about $1200 \mathrm{msec}$ for musicians and 1300 for nonmusicians, in Bigand \& Pineau 19975). Moreover, the finding that these effects last longer in nonmusicians than musicians may reflect the greater difficulties of the nonmusicians to make their decision regarding the consonance of the chord.

Finally, to conclude on a more general note, it is interesting that averages spanning the length of the entire trials show that the ERPs elicited by each chord are similar to those elicited by each word presented in a sentence context (see King \& Kutas, 1995). This may reflect the fact that at some level of processing, the computations involved to extract information for words and chords share some degrees of similarity. However, testing this hypothesis again requires to directly compare the ERPs associated to words and chords in the same experiment. This issue is important as it directly relates to the question of the specificity and modularity of human cognitive functions. Comparing certain aspects of language processing with certain aspects of music processing has already been shown to add important information regarding the specificity of language processing (Besson, Faïta, Czternasty, \& Kutas, 1997; Besson \& Friederici, 1998). In this respect, it is important to note that, as mentioned above, Patel et al. (1998) have shown that similar processes are engaged in processing syntactic/structural aspects in language and music. Moreover, they also reported that a transient negative component was elicited in response to out-ofkey target chords. This negativity peaked around 350 msec and showed a clear right antero-temporal scalp distribution (and was called the right antero-temporal negativity, RATN). The authors hypothesized that it might reflect the use of music-specific syntactic rules, as the left anterior negativity (LAN) reported in language experiments has been hypothesized to reflect first syntactic analyses (Friederici, Pfeifer, \& Hahne, 1993; Neville, Nicol, Barss, Forster, \& Garrett, 1991). Thus, such results clearly illustrate that experiments in music perception not only allow us to understand how the brain processes music, but are also important at a higher level to understand the cognitive architecture of human mental functions. Specifying the functional organization of the brain requires to decompose the different functions into their component operations (see Sergent, 1993). This was the aim of our experiment in studying the relationship between consonance and harmonic context. The next step will be to localize the brain structures involved in processing consonance and harmonic function. Indeed, while some results already allow us to pinpoint the cerebral structures involved in processing some aspects of music perception, such as pitch, rhythm, and timbre (Liégeois-Chauvel, Peretz, Babaï, Laguitton, \& Chauvel, 1998; Platel et al., 1997; Zatorre, Evans, \& Meyer, 1994), fewer studies have been aimed at studying the underlying brain mechanisms responsible for consonance and harmonic processing. Blood, Zatorre, Bermudez, and Evans (1999) studied the brain regions activated by dissonance in a positron emission tomography (PET) experiment. Consonance was manipulated by varying the structure of the accompanying chords of an original melody. Thus, six versions of this melody, from the most consonant to the most dissonant, were presented to nonmusicians who were asked to rate the emotional value of the music. Activity in the right parahippocampus gyrus was correlated with increasing dissonance, whereas activity in right orbitofrontal and medial subcallosal cingulate was correlated with decreasing dissonance. Beisteiner et al. (1999) studied the magnetic marker of harmonic processing (P3m) in an MEG experiment. Series of cadences sounding the tonic (I)-subdominant (IV)-dominant chords (V) were followed by a target tone with different harmonic functions in the context (tonic, third, sixth, or nonharmonic minor second). Highly trained musicians had to silently count the nonharmonic target tones. Such targets elicited a clear $\mathrm{P} 3 \mathrm{~m}$ component, generated in the temporo-parietal areas, and no such component was found for the tonic. The authors concluded that the $\mathrm{P} 3 \mathrm{~m}$ seemed specific to harmonic context violation. However, this interpretation should be considered with caution since the nonharmonic targets were also rare events (probability of occurrence $=.25$ ) that were taskrelevant and, consequently, very likely to elicit P3 components.

\section{CONCLUSION}

In conclusion, the present results provide strong evidence for the independent processing of sensory consonance and harmonic function of the target chords. 
Indeed, the effects of these two factors were never found to interact, whatever the latency ranges considered for analyses. Moreover, the time-course of the sensory and cognitive ERP effects associated with musical expectancy clearly differ in both cases. To summarize, results showed an early effect of consonance, most likely reflecting bottom-up influences, on the amplitude of the N1 component for musicians only, with no effect of the harmonic context. This is taken to reflect the greater abilities of musicians to process the physical attributes of sounds due to their extended musical practice. Then, an early effect of context, most likely reflecting top-down influences, was found for both musicians and nonmusicians on the amplitude of the P3 component in the 200-300msec latency range. This finding reveals that nonmusicians have implicitly internalized the basic rules of musical harmony. Finally, sensory consonance clearly had a large influence on the amplitude of the LPC in the 300-800-msec range; for both musicians and nonmusicians, the LPC was larger to dissonant than consonant chords. The effects of both sensory consonance and harmonic function take the form of increased positivities, either to weakly expected chords, the P3 component, or to dissonant chords, the LPC. As these effects are in close temporal succession and of the same polarity, they were probably confounded in previous experiments, due to component overlap. A model in which top-down processing of the harmonic context and bottom-up processing of the acoustic attributes of the chords occur in parallel, independently, and terminate at different moment in time, accounts well for our findings and shall be tested in further experiments.

\section{METHODS}

\section{Participants}

Twelve musicians (age range: $19-55$ years, mean 32 years; 4 females) and 12 nonmusicians (age range: 2029 years, mean 24 years; 7 females) were paid for participating in the experiment that lasted for approximately $1.5 \mathrm{hr}$. Musicians had at least 10 years of training in classical music. Nonmusicians had no explicit learning of musical theory and did not play any instrument. All participants were right-handed and had normal hearing.

\section{Materials}

Forty sequences of eight chords from Bigand and Pineau (1997) and Pineau and Bigand $(1997)^{6}$ were presented in the experiment. As illustrated in Figure 1a-left, all sequences in the expected target condition ended with an authentic cadence (V-I). However, they differed in several aspects related to the melodic contour of the upper and bass voices, the sequential order of the chords (i.e., the set of roman numerals), and the voicing (the specific pitch height of the component tones). Sequences in the weakly expected target condition were matched to those in the strongly expected target condition. As illustrated in Figure 1a-right, the first six chords were systematically modified, so that the new sequences were in the dominant key. As far as possible, the melodic contour of the outer voices (i.e., soprano and bass voices) remained unchanged, and the changes in pitch were minimal so that the registers remained similar. The last two chords were acoustically identical, but their harmonic functions changed as a function of the context: In one context, the last chord functioned as a tonic chord (I), part of an authentic cadence (i.e., a dominant followed by a tonic chord, $\mathrm{V}-\mathrm{I}$ ), and in the other context, as a subdominant chord (IV) following an authentic cadence. $^{7}$ In order to assess the effect of sensory consonance on harmonic expectancy, the 40 sequences were also played with a dissonant target chord: The final target chords were rendered dissonant by increasing the pitch of the fifth by a semitone. Results of Bigand and Pineau have shown that such augmented fifth chords are indeed perceived as more dissonant than perfect chords when played in isolation, a finding supporting the Hutchinson and Knopoff (1978) theory of chordal dissonance. The intensity of the augmented fifth was the same as for the other tones, thus making the dissonance quite salient. Each sequence was composed of eight successive chords of $700 \mathrm{msec}$ duration each, with no silence between them (duration of a sequence: $5600 \mathrm{msec}$, see Figure 1b).

\section{Apparatus}

All stimuli were generated by an EMT10 Yamaha Sound Expander, which reproduced the piano sound. They were then recorded and played by a personal computer (Compaq) with a music card (Sound Blaster AWE32). The musical sequences were presented to participants through earphones at a comfortable listening level.

\section{Procedure}

Participants were individually tested and seated in a comfortable chair in an electrically shielded room. They were informed that they would be presented with series of eight chords sequences, that the last chord was more or less consonant or dissonant, and that they should respond accordingly by pressing a response key on a sixpoint scale ( $1=$ very consonant; $6=$ very dissonant). The terms "consonant/dissonant" were systematically explained to the nonmusicians as meaning "pleasant/ unpleasant" and "everything seems OK/something seems wrong". In order to avoid the contamination of the ERPs of interest by motor-related potentials, the response was delayed until a row of Xs appeared on 
the screen, $2 \mathrm{sec}$ after the end of each chord sequence. The Xs remained on the screen for the duration of the inter-trial interval (ITI $=2 \mathrm{sec}$ ). Thus, there were $4 \mathrm{sec}$ of silence between the trials (see Figure 1b).

The EEG was recorded from 19 scalp electrodes mounted in an elastic cap and located at standard positions of the International 10/20 system. Eye blinks and vertical deviations from fixation were recorded from an electrode located below the right eye, and the horizontal electrooculogram (EOG) from electrodes located at the outer ocular canthi. All electrodes were referenced to an electrode located over the left mastoid, except for the bipolar horizontal EOG recordings. The EEG was amplified with a bandpass of 0.01 to $30 \mathrm{~Hz}$ and digitized at a rate of $250 \mathrm{~Hz}$. Trials with artifacts due to eye movements, muscle activity, or amplifier blocking were rejected from further analyses. ERPs were recorded for $7800 \mathrm{msec}$, beginning $200 \mathrm{msec}$ before the first-chord onset (baseline), and lasting $2000 \mathrm{msec}$ after the lastchord offset (see Figure 1b). ERPs were first averaged within condition for each participant, and then across. However, since the main interest was in the final chord, the last 2900 of the $7800 \mathrm{msec}$ epochs were reaveraged separately (from $200 \mathrm{msec}$ before final chord onset to 2000 msec after chord offset).

Statistical analyses were computed on these short individual averages to test the differences between four experimental conditions: consonant strongly or weakly expected, and dissonant strongly or weakly expected. The mean amplitudes (i.e., integration of amplitude values over time) were measured within several latency ranges of interest and were submitted to a four-way ANOVA, including expertise (musicians vs. nonmusicians) as a between-subjects factor, and harmonic context (strong vs. weak), sensory consonance (consonant vs. dissonant), and electrodes (17 levels) as withinsubjects factors. In the latency ranges in which the effect of expertise was significant, separate three-way ANOVAs for musicians and nonmusicians were conducted on mean amplitudes, with harmonic context, sensory consonance, and electrodes as factors. The associated $p$ values were adjusted according to the Geisser-Greenhouse correction procedure.

\section{Design}

The 80 chord sequences were presented in two blocks of 40 sequences each. The four experimental conditions were presented in a random order.

\section{APPENDIX}

(A) In the Western musical system, the 12 notes of the chromatic scale are organized in several subsets of seven notes, called diatonic scales. For each scale, seven diatonic chords are possible, each built on a different degree of the scale. Chords built on the first, the fifth, and the fourth scale degree (referred to as tonic, dominant, and subdominant chords, respectively) usually have a more central syntactic function than other chords, the tonic being more important than the dominant or the subdominant. This creates a within-key hierarchy. Western musical system has 24 major and minor keys. Between-key distances refer to the distances separating these keys. Keys sharing a great number of scale notes and chords (e.g., C- and G-major or C-major and A-minor) are very close, while those sharing only a few tones and chords are very far apart (e.g., C-major and F\#-major, or C-major and Eb-minor). A crucial aspect for music cognition is that chords (and notes) belong to several keys, e.g., the $\mathrm{C}$ chord belongs to the C-, F-, G-major keys, and to the A- and E-minor keys. Consequently, their harmonic function varies depending upon the context in which they appear: A C chord functions as a stable tonic chord in a $\mathrm{C}$-major context, and as less stable dominant and subdominant chord in the F- and G-major key contexts, respectively.

According to Bharucha and Krumhansl (1983), a previous musical context generates expectancies that hierarchically important chords will follow. Empirical studies using a priming paradigm provide strong support for this assumption. For example, Bharucha and Stoeckig (1986, 1987) asked participants to decide as quickly as possible if a target chord following a prime chord was in tune. The target and the prime may be harmonically related (C- and $\mathrm{B} b$-major chords), or unrelated (C- and F\#-major chords). The priming effect was shown by: (1) a bias toward judging targets to be in tune when related to the prime and out of tune when unrelated, and (2) shorter response times for in-tune targets when related, and out-of-tune targets when unrelated. According to the authors, a previous musical context generates expectancies for related chords to follow, resulting in greater sensory consonance and faster processing for expected chords. Consistent findings were reported by Schmuckler and Boltz (1994), who used relatively long musical sequences as primes. Our ERP findings and those of Patel et al. (1998) provide converging evidence for the influence of harmonic hierarchy on harmonic expectancy.

(B) In Western music, a strong correlation is often found between the harmonic function of the chords and their frequency of occurrence: the strongest the function, the highest the frequency of occurrence (see Krumhansl, 1990). Thus, the frequency of occurrence of the target chord tended to be higher in the strongly than in the weakly expected condition. However, several results provide evidence that differences in frequency of occurrence are not responsible for harmonic priming effects. First, in Bigand and Pineau (1997), results of multiple regression analyses, with frequency of occurrence and harmonic function of the target chords as factors, showed that the harmonic function of the target was the only variable that contributed significantly to 
response times. Furthermore, recent priming experiments demonstrated that chords repetition does not facilitate the processing of the target chord (Bigand, Tillmann, Manderlier, \& Poulin, in preparation; Bigand, 1999). Moreover, the processing of the target chord is faster and more accurate when primed by a harmonically related chord $(\mathrm{G}-\mathrm{C})$ than when primed by an identical chord $(\mathrm{C}-\mathrm{C})$. Finally, Bigand, Tillmann, Poulin, and D'Adamo (in preparation) directly manipulated the frequency of occurrence and the harmonic function of the target in chord sequences. In one condition, the weakly expected subdominant chord occurred more often in the context than did the structurally expected tonic chord (that never occurred in the context). Results showed that despite of the lower frequency of occurrence of the tonic, its processing was facilitated compared to the processing of the subdominant. Taken together, these results strongly suggest that chord repetition is unlikely to account for the priming effect reported in the present study.

\section{Acknowledgments}

We thank Ron Mangun and three anonymous reviewers for their valuable comments and support. The first author was supported by a fellowship from the French Ministry of Education and Research. This research was supported by a grant from the International Foundation for Music Research to Mireille Besson.

Reprint requests should be sent to Pascaline Regnault, CRNC-CNRS, 31, Chemin Joseph Aiguier, 13402 Marseille Cedex 20, France. E-mail: regnault@lnf.cnrs-mrs.fr.

\section{Notes}

1. The term "sensory processes" refers to the processes called into play by a sensory manipulation of the target chord (i.e., consonant vs. dissonant). The term "cognitive processes" refers to the processes elicited by target manipulation at a cognitive level (i.e., strongly expected vs. weakly expected). However, what we call "sensory" and "cognitive" processes may include processes other than stricly sensory and cognitive, such as perceptual and decisional processes.

2. See Appendix A for a brief description of the Western harmonic hierarchy.

3. Sensory refractory effects have been described when the interval between two stimuli is too short for the system to return to its original state (i.e., the state before the perturbations linked with stimuli presentation) and is usually reflected in a decrease in the amplitude of the exogeneous ERP components.

4. It is equally possible to consider that the results do not reflect an increase in N1 amplitude to consonant chords but rather a decrease in $\mathrm{N} 1$ amplitude to dissonant chords. As both the negativity (N1) and positivity (P2) develop in the same time window, they may overlap, thus resulting in a decrease in N1 amplitude to dissonant chords. We cannot differentiate these two interpretations from the present results.

5. While we did not record RTs in the present experiment, Bigand and Pineau (1997) results can be used for comparative purposes as the same materials were presented in both experiments.
6. Examples of these sequences will be soon on the Web: http://www.u-bourgogne.fr/LEAD/english/personnel/bigand/ bigand.htm.

7. See Appendix B for a discussion about repetition effect in chord sequences.

\section{REFERENCES}

Beisteiner, R., Erdler, M., Mayer, D., Gartus, A., Edward, V., Kaindl, T., Golaszewski, S., Lindinger, G., \& Deecke, L. (1999). A marker for differentiation of capabilities for processing of musical harmonies as detected by magnetoencephalography in musicians. Neuroscience Letters, 277, 37-40.

Besson, M., \& Faïta, F. (1995). An event-related potential (ERP) study of musical expectancy: Comparisons of musicians with non-musicians. Journal of Experimental Psychology: Human Perception and Performance, 21, 1278-1296.

Besson, M., Faïta, F., Czternasty, C., \& Kutas, M. (1997). What's in a pause: Event-related potential analysis of temporal disruptions in written and spoken sentences. Biological Psychology, 46, 3-23.

Besson, M., Faïta, F., \& Requin, J. (1994). Brain waves associated with musical incongruities differ for musicians and non-musicians. Neuroscience Letters, 168, 101-105.

Besson, M., \& Friederici, A. (1998). Language and music: A comparative view. Music Perception, 16, 1-10.

Besson, M., \& Macar, F. (1987). An event-related potential analysis of incongruity in music and other non-linguistic contexts. Psychophysiology, 24, 14-25.

Bharucha, J. J. (1987). Music cognition and perceptual facilitation: A connectionist framework. Music Perception, 5, 1-30.

Bharucha, J. J., \& Krumhansl, C. L. (1983). The representation of harmonic structure in music: Hierarchies of stability as a function of context. Cognition, 13, 63-102.

Bharucha, J. J., \& Stoeckig, K. (1986). Reaction time and musical expectancy. Journal of Experimental Psychology: Human Perception and Performance, 12, 403-410.

Bharucha, J. J., \& Stoeckig, K. (1987). Priming of chords: Spreading activation or overlapping frequency spectra? Perception and Psychophysics, 41, 519-524.

Bigand, E. (1999). An harmonic priming to probe key induction. Expert meeting on tonality induction, 6-9 April 1999, University of Nijmegen and University of Ghent.

Bigand, E., Madurell, E., Tillmann, B., \& Pineau, M. (1999). Effect of global structure and temporal organization on chord processing. Journal of Experimental Psychology: Human Perception and Performance, 25, 184-197.

Bigand, E., Parncutt, R., \& Lerdahl, F. (1996). Perception of musical tension in short chord sequences: The influence of harmonic function, sensory dissonance, horizontal motion, and musical training. Perception and Psychophysics, 58, 125-141.

Bigand, E., \& Pineau, M. (1997). Global context effects on musical expectancy. Perception and Psychophysics, 59, 1098-1107.

Bigand, E., Tillmann, B., Manderlier, D., \& Poulin B. (in preparation). Harmonic priming versus chord repetition effect in music.

Bigand, E., Tillmann, B., Poulin, B., \& D'Adamo, D. (in preparation). Effects of global harmonic context on chord processing: Sensory or cognitive component?

Blood, A. J., Zatorre, R. J., Bermudez, P., \& Evans, A. C. (1999). Emotional responses to pleasant and unpleasant music correlate with activity in paralimbic brain regions. Nature Neuroscience, 2, 382-387.

Boltz, M., \& Jones, M. R. (1986). Does rule recursion make melodies easier to reproduce? If not, what does? Cognitive Psychology, 18, 389-431. 
Carlsen, J. C. (1981). Some factors which influence melodic expectancy. Psychomusicology, 1, 12-29.

Coles, M. G. H., \& Rugg, M. D. (1995). Event-related brain potentials: An introduction. In M. D. Rugg \& M. G. H. Coles (Eds.), Electrophysiology of mind: ERPs and cognition (pp. 1-26). Oxford University Press.

Cuddy, L. L., \& Lunney, C. A. (1995). Expectancies generated by melodic intervals: Perceptual judgments of melodic continuity. Perception and Psychophysics, 57, 451-462.

Donchin, E. (1999). The novelty P3 is not a shifty P300. Communication at the Thirty-Ninth Annual Meeting of Society for Psychophysiological Research, October 6-10, Granada, Spain.

Friederici, A. D., Pfeifer, E., \& Hahne, A. (1993). Event-related brain potentials during natural speech processing: Effects of semantic, morphological and syntactic violations. Cognitive Brain Research, 1, 183-192.

Helmholtz, H. L. F. von (1877). Die Lebre von den Tonempfinundgen als physiologische Grundlage fuer die Theorie der Musik (4.Ausgabe). On the sensations of tone as a physiological basis for the theory of music (A. J. Ellis, Trans., 1885). London: Longmans, Green. Reprint: Dover, New York.

Hillyard, S. A., Hink, R. F., Schwent, V. L., \& Picton, T. W. (1973). Electrical signs of selective attention in the human brain. Science, 182, 177-180.

Hutchinson, W., \& Knopoff, L. (1978). The acoustical component of western consonance. Interface, 7, 1-29.

Janata, P. (1995). ERP measures assay the degree of expectancy violation of harmonic contexts in music. Journal of Cognitive Neuroscience, 7, 153-164.

King, J. W., \& Kutas, M. (1995). Who did what and when? Using word- and clausal-level ERPs to monitor working memory usage in reading. Journal of Cognitive Neuroscience, 7 , 376-395.

Krumhansl, C. L. (1990). Cognitive foundations of musical pitch. Oxford: Oxford University Press.

Krumhansl, C. L. (1995). Music Psychology and music theory: Problems and prospects. Music Theory Spectrum, 17, 53-81.

Levett, C., \& Martin, F. (1992). The relationship between complex music stimuli and the late components of the ERPs. Psychomusicology, 11, 125-140.

Liégeois-Chauvel, C., Peretz, I., Babaï, M., Laguitton, V., \& Chauvel, P. (1998). Contribution of different cortical areas in the temporal lobes to music processing. Brain, 121, 18531867.

Moore, B. C. J., \& Glasberg, B. R. (1983). Suggested formulae for calculating auditory-filter bandwidths and excitation patterns. Journal of Acoustical Society of America, 74, 750753.

Näätänen, R. (1990). The role of attention in auditory information processing as revealed by event-related potentials and other brain measures of cognitive function. Behavioral and Brain Sciences, 13, 201-288.

Näätänen, R., Gaillard, A. W. K., \& Mantysalo, S. (1978). The N1 effect of selective attention reinterpreted. Acta Psychologica, 42, 313-329.

Näätänen, R., \& Picton, T. (1987). The N1 wave of the electric and magnetic response to sound: A review and an analysis of the component structure. Psychophysiology, 24, 375-425.

Neville, H., Nicol, J. L., Barss, A., Forster, K. I., \& Garrett, M. F. (1991). Syntactically based sentence processing classes: Evidence from event-related brain potentials. Journal of Cognitive Neuroscience, 3, 151-165.
Paller, K. A., McCarthy, G., \& Wood, C. (1992). ERPs elicited by deviant endings to melodies. Psychophysiology, 29, 202-206.

Pantev, C., Oostenveld, R., Engelien, A., Ross, B., Roberts, L. E., \& Hoke, M. (1998). Increased auditory cortical representation in musicians. Nature, 392, 811-814.

Parncutt, R. (1989). Harmony: A psychoacoustical approach. Berlin: Springer-Verlag.

Patel, A. D., Gibson, E., Ratner, J., Besson, M., \& Holcomb, P. J. (1998). Processing syntactic relations in language and music: An event-related potential study. Journal of Cognitive Neuroscience, 10, 717-733.

Pineau, M., \& Bigand, E. (1997). Influence du context global sur l'amorçage harmonique. L'Année Psychologique, 97, 385-408.

Platel, H., Price, C., Baron, J.-C., Wise, R., Lambert, J., Frackowiak, R. S., Lechevalier, B., \& Eustache, F. (1997). The structural components of music perception. Brain, 120, 229-243.

Plomp, R., \& Levelt, W. J. M. (1965). Tonal consonance and critical bandwidth. Journal of the Acoustical Society of America, 38, 548-560.

Rauschecker, J. P. (1999). Auditory cortical plasticity: A comparison with other sensory systems. Trends in Neurosciences, 22, 74-80.

Rosner, B., \& Narmour, E. (1992). Harmonic closure: Music theory and perception. Music Perception, 4, 383-412.

Schellenberg, E. G. (1995). Expectancy in melody: Test of the implication-realization model. Cognition, 58, 75-125.

Schmuckler, M. A. (1989). Expectation in music: Investigation of melodic and harmonic processes. Music Perception, 7, 109-150.

Schmuckler, M. A., \& Boltz, M. G. (1994). Harmonic and rhythmic influences on musical expectancy. Perception and Psychophysics, 56, 313-325.

Sergent, J. (1993). Mapping in the musical brain. Human Brain Mapping, 1, 20-38.

Tekman, H. G., \& Bharucha, J. J. (1992). Time course of chord priming. Perception and Psychophysics, 51, 33-39.

Tekman, H. G., \& Bharucha, J. J. (1998). Implicit knowledge versus psychoacoustic similarity in priming of chords. Journal of Experimental Psychology: Human Perception and Performance, 24, 252-260.

Tillmann, B., Bharucha, J. J., \& Bigand, E. (2000). Implicit learning of tonality: A self-organizing approach. Psychological Review 107, 885-913.

Tillmann, B., Bigand, E., \& Pineau, M. (1998). Effects of global and local contexts on harmonic expectancy. Music Perception, 16, 99-118.

Tramo, M. J., Bharucha, J. J., \& Musieck, F. E. (1990). Music perception and cognition following bilateral lesions of auditory cortex. Journal of Cognitive Neuroscience, 2, 195210.

Unyk, A. M., \& Carlsen, J. C. (1987). The influence of expectancy on melodic perception. Psychomusicology, 7, $3-23$.

Verleger, R. (1990). P3-evoking wrong notes: Unexpected, awaited, or arousing? International Journal of Neuroscience, 55, 171-179.

Zatorre, R. J., Evans, A. C., \& Meyer, E. (1994). Neural mechanisms underlying melodic perception and memory for pitch. Journal of Neuroscience, 14, 1908-1919.

Zwicker, E., \& Terhardt, E. (1980). Analytical expressions for critical-band rate and critical bandwidth as a function of frequency. Journal of Acoustical Society of America, 68, $1523-1525$. 